\title{
CAVITATION EROSION DAMAGE IN DIESEL ENGINES WET CYLINDER LINERS
}

\author{
M. A. Hosien and S. M. Selim \\ Mechanical Power Engineering Department, Faculty of Engineering, Menoufyia University, \\ Shebin El-Kom, Egypt
}

\begin{abstract}
An experimental investigation was conducted using vibratory device in order to obtain the effects of the vibration amplitude, pressure, temperature of water and depth of water on the cavitation erosion damage in wet diesel cylinder liners composed of 99 percent pure aluminum. Data indicated that as the depth of water decreases and the temperature increased, the weight loss rate increased, reached a maximum, and then decreased again. In addition, the weight loss rate increased linearly with increasing suppression pressure. Results suggest that the designer should design the engine with large gap between the cylinder liner and the jacket, the value of the cooling liquid temperature should be outside the peak erosion range and high cooling water pressure must be prevented to avoid serious erosion. Light optical photomicrographs of the damaged areas on the test specimen surfaces documents the nature of erosion damage corresponding to various test conditions.

الملفص العربي : أجريت التجارب باستخدام جهاز اهتزازي من أجل الحصول على الآثار المترتبة على سعة الاهتز از و الضغط ودرجة حر ارة الماء الكاء وعمق تجويف المياه

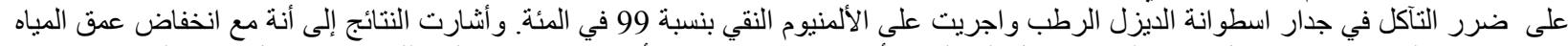

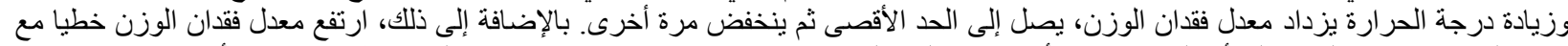

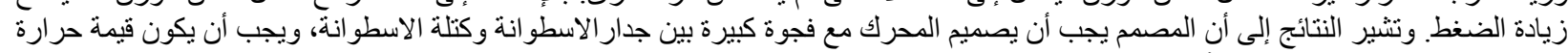

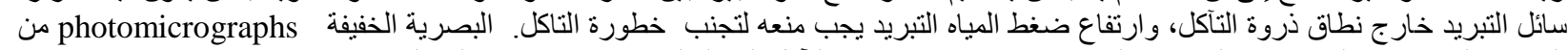
المناطق المتضررة على عينات السطوح المختبرة تؤكد طبيعة اضرار التآكل المقابلة لظروف الاختبارات المختلفة.
\end{abstract}

Keywords: Cavitation, Erosion, Diesel engine, Cylinder liner.

\section{INTRODUCTION}

Cavitation erosion phenomenon of diesel engine wet cylinder liners is a major problem for designers and users of high speed, high output diesel engines. This phenomenon has been recognized for about 65 years. Cavitation erosion damage of cylinder liner is caused by the collapse of cavitation bubbles produced in the cooling water as a result of cylinder liners vibration. The pressure produced by the collapse of cavitation bubbles is often strong to produce erosion damage in cylinder liners.

The vibration of the cylinder is mainly due to the impact of piston against a cylinder wall as a result of sidewise motion of the piston across the cylinder clearance space. This is due to the reversal of the direction of the cross force component of connectingrod force, i.e., piston slap.

Early papers of Joyner [1] , Clegg [2] and Brun [3] reported the pitting erosion of cylinder liners due to the collapse of cavitation bubbles on the surface of the cylinder liners.

Speller and La Que [4] was the first to realize that the damage of cylinder liner is entirely caused by the collapse of cavitation bubbles. Leith [5] stated that "the worst pitted area is located on the water side of the liner exactly where the 'side slap' of the piston takes place during the power stroke". Tests conducted by Leith [5] and Hobbs and Rachman [6] illustrated that cavitation damage may be reduced using commercial additives to the coolant liquid.

Mahle Gmb [7] reported that two main factors control the cause of the cavitation in cylinder liners. These factors are the flow conditions for the coolant and the vibrations of the cylinder wall. Yu-Kang et al. [8] reviewed published researches on the cavitation erosion problem of diesel engine wet cylinder liners. They discussed the contradictory findings in these researches. When a severe cavitation erosion of the cylinder liner occurs, a complete penetration of the surface of the cylinder liner takes place and the engine oil will flow into the cooling water when the engine is running and the opposite will occur when the engine is shut-down. This will reduce the engine life and reliability. Kessler et al. [9] conducted a numerical study to analyse the water flow inside MWM INTERNATIONAL's highspeed diesel engine, in order to determine possible cavitation regions, which can reduce the heat transfer efficiency. Based on their results, a modification on the geometry leads to an avoidance of the occurrence of cavitation at water jacket regions. Saleh et al. [10] have studied experimentally the effect of temperature on the 
wear particles produced by vibratory cavitation erosion tests on A199.92 in distilled water. Their results showed that the test liquid temperature affects both the rate of erosion and the average particle size. Hattori and Tanaka [11] have experimentally studied the influence of temperature and air content on cavitation erosion using a vibratory apparatus. Their results indicated that erosion increases with increased temperature up to 50 ${ }^{\circ} \mathrm{C}$ followed by a decrease with rising the temperature. Hattori et al. [12] and [13] have studied the influence of liquid temperature on erosion and liquid properties on cavitation erosion in liquid metal.

Chen and Leng [14] carried out ultrasonic vibratory cavitation erosion tests to study the cavitation erosion protection performance of heavy-duty engine coolants. It was concluded that "with the extension of ultrasonic vibration test time, the anti-cavitation erosion protection performance for cast iron was reduced". Obviously there is little published information on various factors affects cavitation erosion in cylinder liners. This is because much research effort has been concentrated upon the resistance of materials to cavitation erosion and its relation to various physical and metallurgical properties.

In addition, it seems that most of measurements were carried out in vibratory facilities with conditions far from real engine operation conditions.

Apparently, deep knowledge of the factors, cause and effect of cavitation erosion of cylinder liners are required to avoid serious damage of wet liners.

Because of this situation, the work, reported here in brief, is intended to study the effects of depth between the liner and the water jacket, and static pressure and temperature of cooling water on the cavitation erosion. In addition, the present study is carried out in simple vibratory device at test conditions nearly simulate the real operating conditions for diesel engines wet cylinder liners.

\section{EXPERIMENTAL DETAILS}

\subsection{Experimental Equipment}

The equipment used in the present investigation is a simple vibratory device in which vibration frequency and amplitude can be varied independently. This vibratory device simulates the vibrations of the cylinder-liner.

Figure 1 shows the experimental arrangement. The vibrator was driven by a 1000 Watt variable speed universal motor. The face diameter of the vibrator end is $25 \mathrm{~mm}$. The amplitude of vibration could be varied from zero to $4 \mathrm{~mm}$. The maximum vibration frequency is of the order of $1000 \mathrm{~Hz}$. The pressure wave generated resulted in the formation of cavitation cloud in the gap between the vibratory end and the face of the specimen. Specimens exposed to cavitation attack were flushmounted in a specimen holder. The specimen holder was fixed to the apparatus frame and positioned coaxial with the vibratory end.
The specimen holder was used to ensure that the specimen can be taken out for measurements and placed back precisely at the same position to continue testing. The vibratory end was mounted by an $\mathrm{O}$ - ring arrangement into a sealing flange that the air space between water surface and flange can be pressurized as desired. An electric heater was mounted into the water container to maintain the water at the required temperature.

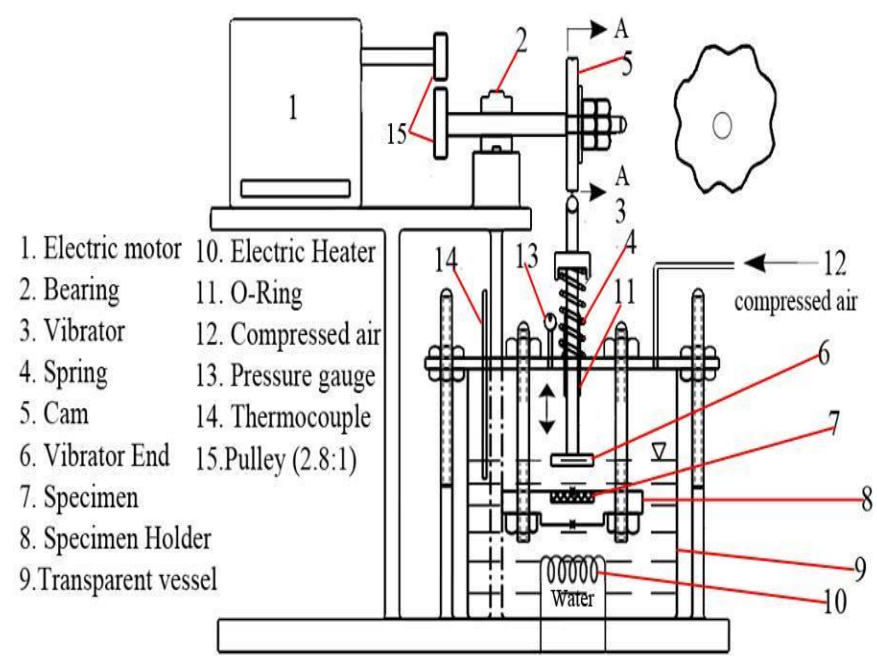

Figure1. Diagrammatic arrangement of experimental vibratory apparatus.

\subsection{Tests Performed and Procedures}

The cavitation erosion tests were divided into constant temperature sets for varying static suppression pressure and constant pressures sets for varying water temperature with constant water depth, vibration frequency and amplitude. Six temperatures, ranging from 40 to $115{ }^{\circ} \mathrm{C}$, four pressures, ranging from 1 to 4 atm. and four water depth values ranging from 2 to $8 \mathrm{~cm}$ were used. The expected errors in measuring frequency, amplitude, depth of water and temperature of water are $\pm 2 \%, \pm 3 \%, \pm 1.5 \%$ and $\pm 2 \%$ respectively.

The experimental tests were performed to study the effects of various parameters on the weight loss rate produced by the collapse of cavitation bubbles. Tap water from the laboratory of Faculty of Engineering, Menoufia University was used.

All test specimens for cavitation erosion were prepared from fabricated (no heat treatment) commercially pure aluminum rods free from scratches and other surface imperfections. This aluminum is $99 \%$ pure (SIC, B.S.1470) with the remaining percentage composed of iron, silicon, and copper with trace amount of zinc and manganese. The Vickers hardness value obtained for $99 \%$ pure aluminum was $40(400 \mathrm{MPa})$. In the present tests, the temperature range employed $\left(30-115^{\circ} \mathrm{C}\right)$ is not enough to cause significant variation in its corrosion resistance. Specimens were polished to obtain a smooth specimen surface. 
An electronic balance of capacity $200 \mathrm{mg}$ and sensitivity $0.1 \mathrm{mg}$ was used to obtain the loss in the weight of test specimen.

The specimen was initially weighed and mounted in the specimen holder, then exposed to cavitation for the desired length of time, after which it was removed from the test stand and reweighed. Before each weighing, the specimen was cleaned and dried. For weight loss/time studies, the specimen was repeatedly subjected to cavitation attack for definite intervals of time until measurements for the desired total test time had been obtained.

The tests were divided into constant temperature sets for varying suppression pressure and constant suppression pressure sets for varying temperature. The suppression pressure is defined as the pressure above vapour pressure. Common parameter conditions were used in evaluating the effect of these two primary variables. Five temperatures ranging from 30 to $115^{\circ} \mathrm{C}$ and four pressure values ranging from 1 to 4 atm were used. No tests were made for pressures greater than 4 atm because of equipment limitations. For all the present erosion tests, the vibrator was operated at $0.15 \mathrm{~mm}$ amplitude, $1000 \mathrm{~Hz}$ and $1.1 \mathrm{~cm}$ separation distance between the vibratory end and the surface of the specimen.

\subsection{Repeatability of Weight Loss Measurement}

Some preliminary weight loss tests were performed on twelve specimens to assess the repeatability of weight loss measurement. The specimens were eroded one after the other at the same test conditions and the weight loss measured after 2 hours of exposure to cavitation attack. Statistical analysis of the weight loss data illustrated that 95 percent confidence limits of the erosion data are \pm $0.9 \mathrm{mg}$ or \pm 3.0 percent, for weight loss at $2 \mathrm{hrs}$.

\subsection{Pattern of Vibratory Cavitation}

Direct visual observations by the aid of the naked eye using stroboscopic light through the transparent vessel indicated that a mass of bubbles (i.e. cloud) appeared to radiate outwards. The cavitation bubbles believed to be produced radially are actually born with a vertically scattered distribution within a semi-spherical space. In the case of $2 \mathrm{~cm}$ water depth, cluster of bubbles appears on the center of the vessel bottom, which sometimes disappears again, but mostly stays during the whole period of existence of the cloud.

\section{RESULTS AND DISCUSSION}

In this section description and discussion of the weight loss measurements results which were achieved throughout the experiments are presented.

\subsection{Effect of Water Depth}

Figure 2 shows two hours cumulative weight loss of aluminum specimens as a function of water depth between the vibratory end and the specimen surface.
This Figure shows that the weight loss increases with increasing the water depth, reaches a maximum and then decreases with increasing the water depth.The maximum cavitation weight loss of the aluminum specimen occurs at approximately $1.1 \mathrm{~cm}$ water depth.

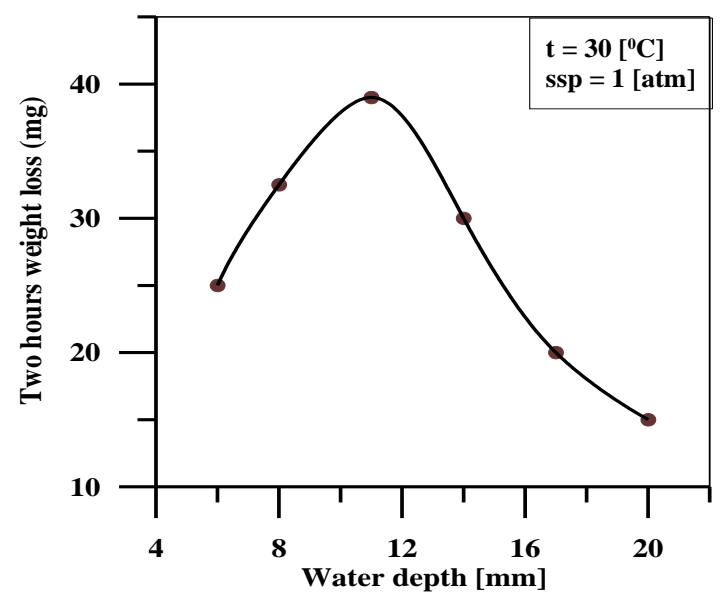

\section{Figure 2. Two hours weight loss as a function of water depth $(t)$.}

Figure 3 illustrates the detailed photograph-based observations of the specimens exposed to cavitation by optical microscopy at various water depths. Figure 3 shows that the cavitation erosion damage is often confined to a rather small area and appears as a deep drilling of the specimen. This is because the collapse of bubbles occurs periodically and impacts the specimen surface at almost the same place. Figure also shows that the maximum weight loss occurs at $1.1 \mathrm{~cm}$ water depth. The same trend had been observed by Vyas and Preece, [15] and Singer and Harvey [16].

There are two possible explanations for this maximum erosion. In the first, the stress which creates the cavities within a liquid is attenuated with increasing distance from the vibratory end and therefore the number of cavitation events would be expected to decrease in a similar manner. However, the number of cavities formed, assuming a uniform nuclei distribution, will depend upon the volume of liquid between specimen and vibratory end. Thus, for a small values of water depth, the number of nuclei in the volume of liquid between vibratory end and the specimen will restrict the total number of cavitation events and hence the rate of erosion. It will be expected, therefore, that the maximum weight loss will occur at a critical water depth. In the second, for cavitation to occur, the liquid must re-enter the region between the vibratory end and the specimen during each tension stroke of a vibration cycle. As the distance between the vibratory end and the specimen is reduced, the extent to which this occurs will decrease and thus cavitation damage, as measured by weight loss of the specimen, will be reduced. This effect, when combined with the attenuation of the stress cavitating the liquid with distance from the vibratory end, 
will result in the observed maximum erosion with water depth. This distance of $1.1 \mathrm{~cm}$, at which maximum erosion occurs, was used for all tests reported herein.

The existence of a peak in erosion is of practical significance because it relates directly to the gap between the cylinder liner and water jacket. Therefore, for given conditions of amplitude, frequency, temperature, etc., there is an optimum spacing for erosion damage which designers of diesel engine would be well advised to avoid.

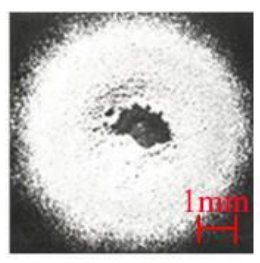

$\mathrm{t}=0.06 \mathrm{~cm}$

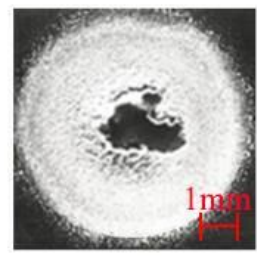

$\mathrm{t}=1.4 \mathrm{~cm}$

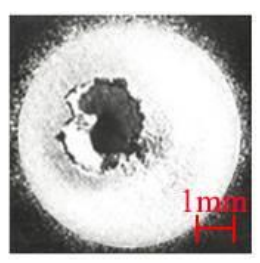

$\mathrm{t}=1.1 \mathrm{~cm}$

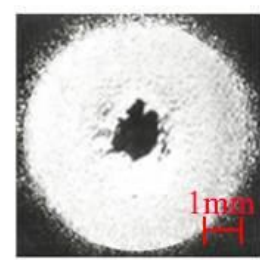

$\mathrm{t}=2.0 \mathrm{~cm}$
Figure 3. Photographs of the damage at various water depths.

\subsection{Effect of Water Temperature}

Figure 4 shows typical variation of cumulative weight loss with the test duration for various temperatures and at constant pressure. This Figure is representative of the curves found in all the present weight loss tests. The portions of the weight loss curves considered to be of constant slope, i.e., steady-state zones are taken to be the weight loss rates.

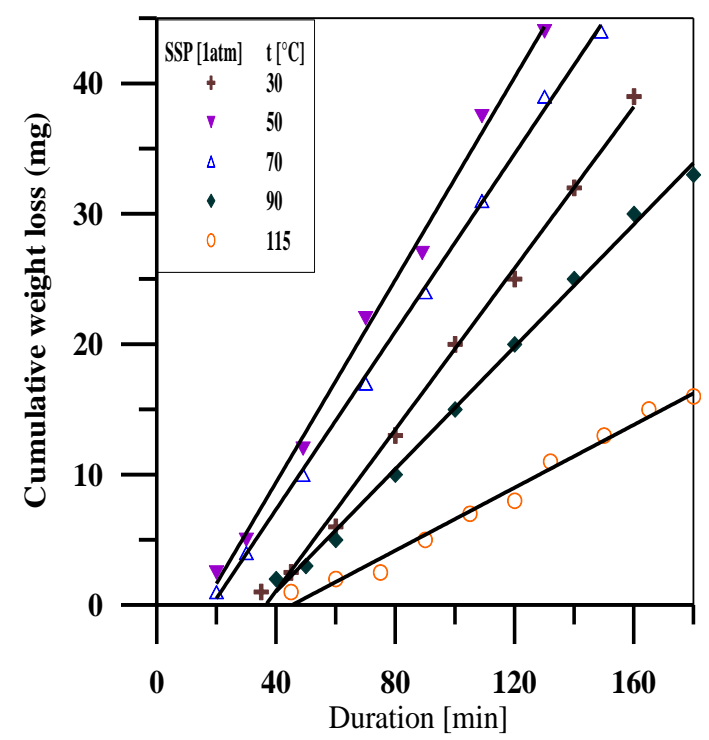

Figure 4. Variation of cumulative weight loss with test duration at various water temperatures.
Figure 5 shows corresponding weight loss rates as a function of temperature at different suppression pressures. This Figure indicates that the weight loss rate increases with the increase of temperature, reaching a maximum value between 50 and $70{ }^{\circ} \mathrm{C}$, and then decreases with the increase of temperature towards the boiling temperature value. Similar trend was reported by Singer and Harvey [16], Dular [17] and Li et al. [18]. Photographs of damaged specimens at various water temperatures are shown in Figure 6. This Figure supports the present finding of the effects of temperature on erosion.

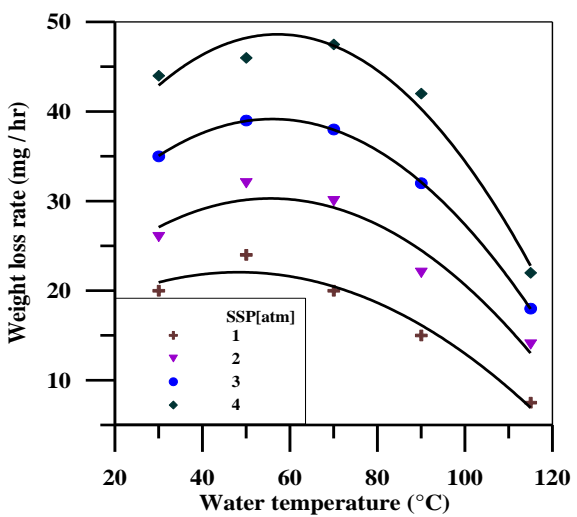

Figure 5. Weight loss rate as a function of water temperature at various static suppression pressures.

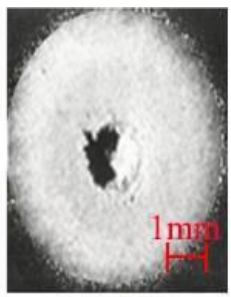

$\mathrm{T}=30^{\circ} \mathrm{C}$

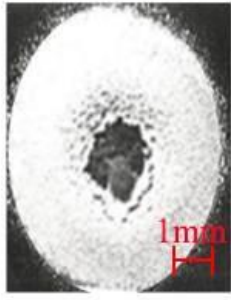

$\mathrm{T}=90^{\circ} \mathrm{C}$

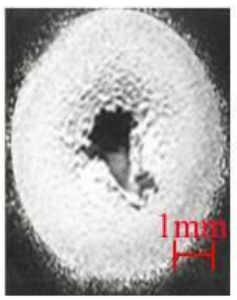

$\mathrm{T}=50^{\circ} \mathrm{C}$

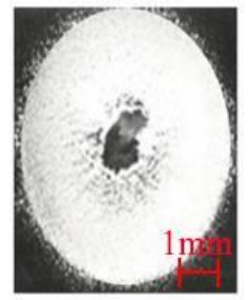

$\mathrm{T}=115^{\circ} \mathrm{C}$

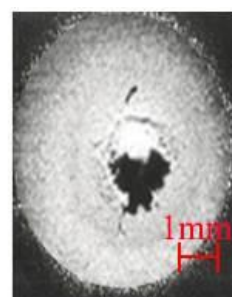

$\mathrm{T}=70^{\circ} \mathrm{C}$
Figuger 6. Photographs of the specimen surface damage at various temperatures at $p=2$ bar.

The effects of varying the temperature on the erosion rate arise from several factors, including; (i) changes in viscosity, vapor pressure, surface tension, and density of the liquid; (ii) thermodynamic effects on bubble growth and collapse; and (iii) changes in the dissolved gas content of the liquid. 
The decrease in erosion rate at temperatures approaching the boiling point is generally considered to be due to the increase in vapour pressure. This increase in vapour pressure results in a decrease in the stress produced by bubble collapse due to smaller pressure differences inside and outside the bubbles. At low temperatures (less than the temperature at which maximum erosion temperature) the increased dissolved gas content leads to a higher rate of diffusion of gases across cavity boundaries. This leads to a decrease in the stress produced by bubble collapse. As the temperature is increased, the solubility of gases in water decreases and erosion rates increase correspondingly. In addition, the low erosion rates at low temperatures should be attributed to the high viscosity of the liquid and to its high surface tension.

The values of temperature for maximum weight loss rate, Fig. 5, depend on the pressure. This is mainly because the variation of dissolved gas content with pressure tends to shift the curves sideways in temperature direction.

\subsection{Effect of Static Suppression Pressure (SSP)}

From the photographs of Figure 7, it is obvious that the heavily damaged area was reduced in size but the depth of damage increased as the pressure was increased. This is because an increase of suppression pressure would reduce the extent of the cavitating field, concentrating it toward the centerline where the pressure oscillations induced by the vibratory end motion are maximum.

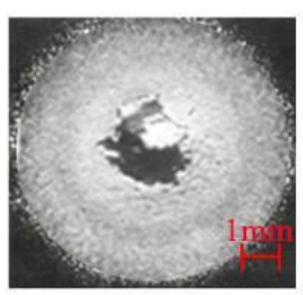

$\mathrm{P}=1 \mathrm{~atm}$

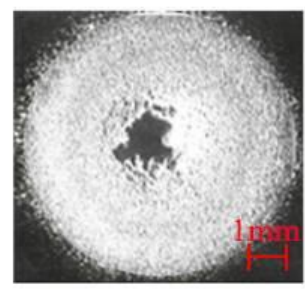

$\mathrm{P}=3$ atm

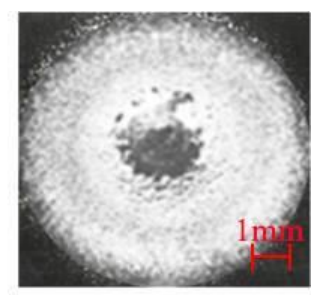

$\mathrm{P}=2$ atm

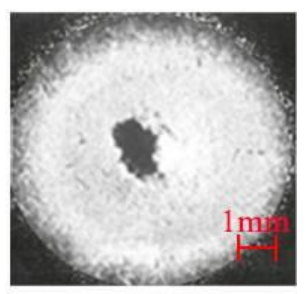

$\mathrm{P}=4$ atm
Figure 7. Photographs of damage areaon the specimen surface at various pressures with constant temperature of $65^{\circ} \mathrm{C}$ and $\mathrm{t}=1.1 \mathrm{~cm}$.

Figure 8 shows the effect of the suppression pressure on the weight loss rate at constant water temperature ranged from 30 to $115^{\circ} \mathrm{C}$. This Figure indicates that for a given temperature, the weight loss rate increases linearly with increasing pressure for the pressure range considered (1- $4 \mathrm{~atm})$.

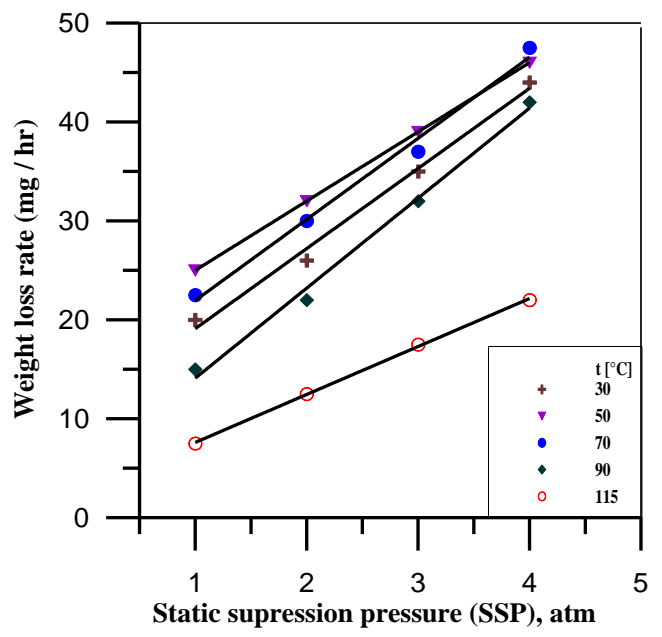

Fig. 8. Variation of weight loss rate with suppression pressure at various temperatures.

The increase of suppression pressure should affect damage rate through at least two competing mechanisms: (i) the number and average diameter of bubbles would be decreased as the suppression pressure is increased, assuming constant amplitude and frequency of the vibratory end and temperature of water; and (ii) the collapse velocities would be greater, and therefore, the radiated pressures are increased for a given diameter of bubble. In the present tests apparently the second mechanism is overriding. However, it is obvious that the damage rate will be decreased eventually if the suppression pressure is raised sufficiently, since cavitation will cease entirely for a sufficiently high pressure.

The present result implies that in cylinder liners where cavitation occurs in high-pressure regions, damage to the cylinder liners may be much greater than could be expected normally from cavitation attack at atmospheric pressure.

\section{CONCLUSIONS}

The important conclusions that can be drawn are as follows:

1. Erosion tests indicated that the weight loss increased as the water depth increased reaching a peak and then decreased again. Also it was observed that the weight loss rate increased and then decreased again with increasing water temperature. The maximum damage temperature ranged from $50{ }^{\circ} \mathrm{C}$ to $70{ }^{\circ} \mathrm{C}$ depending on the suppression pressure. In addition, the weight loss rate increased linearly with the increasing the suppression pressure.

2. The photograph -based observations of the cavitation damage area on the specimen's surface confirmed the present results at various test conditions.

3. Cavitation erosion results suggest that the designer should design the engine with large depth between the liner and the jacket, the value of the engine 
cooling liquid temperature should be located outside the peak erosion range and high engine cooling liquid should be avoided to prevent serious cavitation erosion.

\section{REFERENCES}

[1] Joyner, J.A., "Reduction of cavitation pitting of diesel- engine cylinder liners", SAE Technical Paper 570030 (1957).

[2] Clegg, J.P., "Water-side attack on cylinder liners", Report issued by BICERA, Part II, (1959).

[3] Brun, R.," Cavitation corrosion of diesel engine liners on french national railways", Symp. on Cavitation Corrosion and its Prevention in Diesel Engines, British Rail Board (1966).

[4] Speller, F.N. and La Que, F.L, "Water side deterioration of diesel engine cylinder liners", Corrosion, Vol. 6, No. 7(1950), pp. 209-215.

[5] Leith, W.C., "Cavitation damage of metals", Department of Mechanical Engineering McGill University Montreal March (1957).

[6] Hobbs, J.M. and Rachman, D., "Current knowledge of cavitation phenomena, their Prevention or Application", Eng. Ship Scotland 114(1971), 207260.

[7] Mahle GmbH, "Pistons and engine testing", ATZ/MTZ- Fachbuch. Wiesbaden Germany: Springer Vieweg (2012).

[8] Yu-Kang, Z., Jiu-Gen, H. and Hammitt, F. G., "Cavitation erosion of diesel engine wet cylinder liners", Wear, Volume 76 Issue 3 (1982), pp 321328.

[9] Kessler, M.P., Kruger, M., Ataídes, R., de la Rosa Siqueira, C., Argachoy, C. and Mendes, A.S. ," Numerical analysis of flow at water jacket of an internal combustion engine", No. 01-2711 (2007), SAE Technical Paper.
[10] Saleh, B., Abouel-Kasem, A. and Ezz El-Deen A., "Behavior based on analysis of erosion particles", J. Tribol, 132(4) (2010), 041601.

[11] Hattori, S. and Tanaka, Y., "Influence of air content and vapour pressure of liquids on cavitation erosion", Trans. Jpn. Soc. Mech. Eng. 68 B (2002), 13-136.

[12] Hattori, S., Inoue, F. and Fukuyama T, "Influence of temperature on erosion by a cavitating liquid jet", Wear, 260 (2006), 1217-1223.

[13] Hattori, S., Inoue, F., Watash, K. and Hashimoto, T., "Effect of liquid prosperities on cavitation erosion in liquid metals", Wear 265 (2008), 16491654.

[14] Chen, J. and Leng, G. "The study of cavitation erosion protection performance of heavy-duty engine coolants", Applied Mechanics and Materials, Vol. 651-653 (2014), pp 948-952.

[15] Vyas, B. and Preece, C.M. (1976),"Stress produced in a solid by cavitation", J. Appl. Phys., 47 (12) (1976), p. 5133.

[16] Singer, B.G. and Harvery, S.J., "Gas content and temperature effects in vibratory cavitation tests", Wear, 52 (1979).

[17] Dular, M. (2016), "Hydrodynamic cavitation damage in water at elevated temperature", Wear, 346 (2016), 78-86.

[18] Li, Z., Han, J., Lu, J., Zhou, J. and J. Chen, J., "Vibratory cavitation erosion behavior of AISI 304 stainless steel in water at elevated temperatures", Wear, 321 (2014), 33-37. 